\title{
Preclinical trial on the use of doxycycline for the treatment of adenocarcinoma of the duodenum
}

\author{
HECTOR R. GALVÁN-SALAZAR ${ }^{1-3}$, ALEJANDRO D. SORIANO-HERNÁNDEZ ${ }^{1,2}$, \\ DANIEL A. MONTES-GALINDO ${ }^{2}$, GABRIEL CEJA ESPÍRITU ${ }^{1,3}$, JOSÉ GUZMAN-ESQUIVEL ${ }^{3}$, \\ IRAM P. RODRÍGUEZ-SÁNCHEZ ${ }^{4}$, OSCAR A. NEWTON-SÁNCHEZ ${ }^{1}$, MARGARITA L. MARTINEZ-FIERRO ${ }^{5}$, \\ XÓCHITL G. BRISEÑO GÓMEZ ${ }^{2}$, AUGUSTO ROJAS-MARTÍNEZ ${ }^{6}$ and IVÁN DELGADO-ENCISO ${ }^{1,2}$ \\ ${ }^{1}$ School of Medicine, University of Colima, Colima $28040 ;{ }^{2}$ State Cancer Institute, State Ministry of Health of Colima; \\ ${ }^{3}$ Zone No. 1 General Hospital General of the Mexican Social Security Institute (IMSS), Colima 28000; ${ }^{4}$ Department of \\ Genetics, School of Medicine, Autonomous University of Nuevo León (UANL), Monterrey, Nuevo León 64460; \\ ${ }^{5}$ Molecular Medicine Laboratory, Academic Unit of Human Medicine and Health Sciences, Autonomous University \\ of Zacatecas, Zacatecas 98160; ${ }^{6}$ Center of Research and Development in Health Sciences \\ and School of Medicine, UANL, Monterrey, Nuevo León 64460, Mexico
}

Received November 23, 2016; Accepted March 24, 2016

DOI: $10.3892 /$ mco.2016.1013

\begin{abstract}
Adenocarcinoma of the duodenum comprises $50-70 \%$ of duodenal tumors. There is an increase in extracellular matrix metalloproteinases in this disease and it has been suggested that they play an important role in the development and pathology. Therefore, new therapeutic recommendations based on inhibitors of these enzymes, such as doxycycline, are under investigation. The cytotoxic effect of doxycycline was evaluated in the HuTu- 80 duodenal adenocarcinoma cell line and its antitumor effect was determined in an immunodeficient murine model. A $10-\mu \mathrm{M}(4.4 \mu \mathrm{g} / \mathrm{ml})$ concentration of doxycycline was capable of causing apoptosis in $90 \%$ of the culture cells. Doxycycline was also responsible for a decrease in tumor growth and an increase in the survival of the mice with HuTu-80-cell tumors. These results suggest that doxycycline is a potential cytotoxic and antitumor agent effective in the treatment of adenocarcinoma of the duodenum.
\end{abstract}

\section{Introduction}

Adenocarcinoma of the duodenum comprises $50-70 \%$ of duodenal tumors; however, it has an overall low incidence rate, as it represents only $0.3-0.4 \%$ of all intestinal tumors $(1,2)$, and it has not been extensively investigated. Adenocarcinoma of the duodenum is usually detected at an advanced stage, due to its non-specific clinical presentation. Curative attempts are

Correspondence to: Dr Iván Delgado Enciso, School of Medicine, University of Colima, 333 Universidad Avenue, Colonia Las Víboras, Colima 28040, Mexico

E-mail: ivan_delgado_enciso@ucol.mx

Key words: cancer, treatment, doxycycline, duodenum, cytotoxic effect based on surgery, but the overall survival rate is very low $(25 \%$ at 5 years) (1). Chemotherapy and radiation are considered to make a minimal contribution to disease-free survival (2). As this disease is uncommon, there has been little investigation on new treatments, which are necessary for these patients.

The true etiology of adenocarcinoma of the duodenum is not yet known. However, it has been suggested that the extracellular matrix metalloproteinases (MMPs) play an important role, as they are overexpressed in tumor tissue and participate in histological remodeling, which is a characteristic of this disease. New therapeutic recommendations based on MMP inhibitors are currently under investigation. Such is the case of doxycycline, which is considered to be a potent inhibitor of MMP activity (3). Likewise, doxycycline may also inhibit the proteins associated with inflammation (4), which may also exert an antineoplastic effect. Therefore, doxycycline and other MMP inhibitors are considered as potential antineoplastic agents. The aim of the present study was to determine the cytotoxic and antitumor effects of doxycycline in in vitro (cell culture) and in vivo (immunodeficient mice) models of adenocarcinoma of the duodenum.

\section{Materials and methods}

Antineoplastic effect. HuTu-80 human duodenal adenocarcinoma cells ( $1 \times 10^{4}$; American Type Culture Collection number: HTB-40) were plated in 96-well dishes, with Dulbecco's modified Eagle's medium (DMEM) with $2 \mathrm{mM}$ of L-glutamine (Sigma-Aldrich, Saint Louis, MO, USA), supplemented with $2 \%$ fetal bovine serum (Gibco, Grand Island, NY, USA). After $12 \mathrm{~h}$, doxycycline (Sigma-Aldrich) was added to a concentration of 5 and $10 \mu \mathrm{M}$, in a total volume of $200 \mu \mathrm{l} /$ well. To determine the antineoplastic effect, an assay was performed at $72 \mathrm{~h}$, in which metabolic activity was measured with a redox agent (Alamar Blue ${ }^{\circledR}$ ). There was reduced cellular activity in the presence of doxycycline, compared with unexposed cells 
(100\% viability reference). These experiments were performed in triplicate, according to the manufacturer's instructions (Biosource, Nivelles, Belgium). The incubation conditions were $37^{\circ} \mathrm{C}, 5 \% \mathrm{CO}_{2}$, and $97 \%$ relative humidity.

In vivo assay. A total of 16 male mice were used for the duodenal adenocarcinoma murine model. The animals were Foxn1 nu strain mice (Harlan Laboratories, Mexico City, Mexico) and were 4 weeks old, athymic and immunodeficient. The mice were inoculated in the dorsal region with $1 \times 10^{5} \mathrm{HuTu}-80$ human duodenal adenocarcinoma cells. After 10-15 days, when a tumor of $\sim 4 \mathrm{~mm}$ in diameter was detected, the mice were randomly selected and assigned into two groups of $(n=8$ per group). A daily intraperitoneal dose of $40 \mathrm{mg} / \mathrm{kg}$ doxycycline in $100 \mu \mathrm{l}$ DMEM was administered to the experimental group, whereas only $100 \mu \mathrm{l}$ of the medium was administered daily to the control group. According to previous studies on rats or mice, this dose of doxycycline is capable of inhibiting proinflammatory cytokines and MMPs $(5,6)$. It should be mentioned that doses that are 5 times higher are commonly used in these animal models (7). This treatment was continued for 25 days and tumor volume was measured every 5 days (the length, height and width of the tumor were measured with a vernier). Tumor volume was calculated as previously described (8). The tumor volume that was determined immediately prior to treatment initiation was considered as the $100 \%$ value. The survival of the mice was analyzed up to day 80. Following the protocol and ethical considerations, the animals were euthanized by cervical dislocation when the tumor reached $25 \mathrm{~mm}$ in any of its dimensions. All experiments were conducted with respect to animal rights, and the mice were treated humanely, ensuring their general well-being. The study was approved by the Institutional Bioethics Committee and followed the Mexican Official Guidelines NOM-062-ZOO-1999 that regulates the use of laboratory animals for research.

Statistical analysis. Tumor growth curves were analyzed through statistical comparison with non-parametric tumor growth curve methods (free distribution) (8). Animal survival was evaluated using Kaplan-Meier curves, which enabled the proportion of events observed on a given day to be calculated for each day (MedCalc program version 10 for Windows Vista; MedCalc Software, Mariakerke, Belgium).

\section{Results}

In vitro assay. After being exposed to doxycycline for $72 \mathrm{~h}$, a cellular viability of $55 \pm 2 \%$ and $10 \pm 1.6 \%$ at 5 and $10 \mu \mathrm{M}$, respectively, was determined. These concentrations corresponded to 2.22 and $4.44 \mu \mathrm{g} / \mathrm{ml}$. The maximum plasma concentration attainable in humans varies from 1.5 to $3.6 \mu \mathrm{g} / \mathrm{ml}$ after therapeutic doses of doxycycline. Thus, the concentrations employed in this study were similar to those that can be obtained in human plasma at therapeutic doses.

In vivo assay. Starting on day 15 of the experiment, a statistically significant reduction in the percentage of tumor growth was observed in the doxycycline group, which increased over time $(\mathrm{P}=0.0001)($ Fig. 1A). This result was in accordance with the higher survival in the mice of the doxycycline

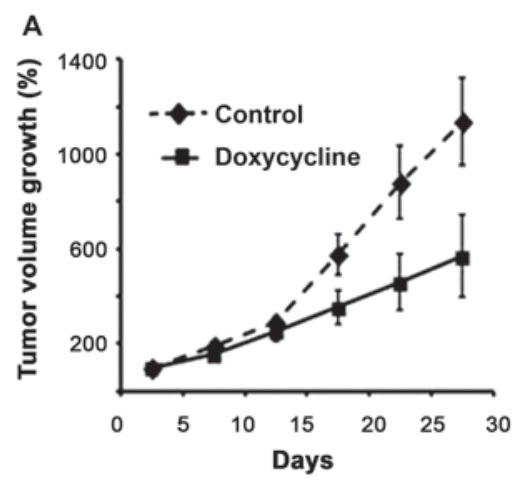

B

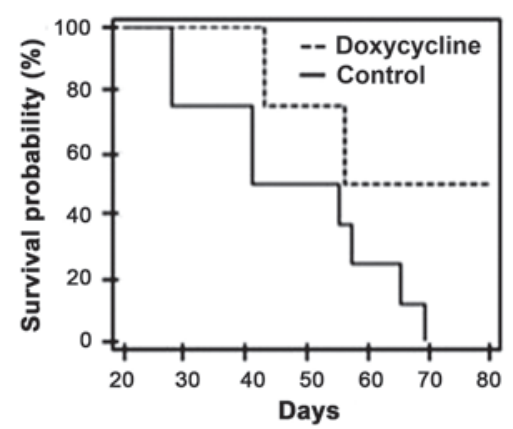

Figure 1. Tumor volume growth and survival curves of immunodeficient mice implanted with human duodenal adenocarcinoma cells. (A) The group treated with doxycycline presented with a lower rate of tumor growth compared with the control group $(\mathrm{P}=0.0001)$. This graph shows the median and standard error. (B) The mice in the group treated with doxycycline presented with higher survival compared with that of the control group $(\mathrm{P}=0.03)$.

group (Fig. 1B) ( $\mathrm{P}=0.03)$. The Kaplan-Meier curve shows that after the last day of follow-up (day 80), 50\% of the experimental group animals remained alive, whereas the animals in the control group were euthanized before the tumors reached a size of $25 \mathrm{~mm}$ in diameter.

\section{Discussion}

The in vitro and in vivo assays demonstrated that doxycycline exerts a significant antineoplastic and antitumor effect on duodenal adenocarcinoma. These data are consistent with the study by Sagar et al (9), which demonstrated cytotoxic activity of doxycycline in colorectal cancer cells (HT29 cell line). To the best of our knowledge, there are no other studies on intestinal neoplasias. However, doxycycline has been tested in vitro in different neoplasias. It has been demonstrated that sensitivity to doxycycline varies depending on the type of cancer. In HT29 colorectal cancer, a concentration of $10 \mu \mathrm{g} / \mathrm{ml}$ induces G0/G1 cellular arrest, whereas a concentration of $20 \mu \mathrm{g} / \mathrm{ml}$ causes apoptosis through the mitochondrial pathway $(10,11)$. However, prostate cancer and glioma cells must exceed these concentrations in order to cause cell death $(12,13)$. In the in vitro assays of the present study, apoptosis of duodenal adenocarcinoma cells was caused even at the low concentrations of 2.2 and $4.4 \mu \mathrm{g} / \mathrm{ml}$ (5 and $10 \mu \mathrm{M}$, respectively). These concentrations are lower compared with those reported for other types of cancer and may indicate that duodenal adenocarcinoma exhibits a greater sensitivity to the cytotoxic effect of doxycycline. In contrast to previous reports, the concentrations of doxycycline used in this 
study are attainable in human plasma (1.5-3.6 $\mu \mathrm{g} / \mathrm{ml})$ following administration of therapeutic doses of the drug.

Various action mechanisms of the antineoplastic effect of doxycycline have been proposed. One is the induction of apoptosis (14), possibly due to caspase-3 elevation and inhibition of the action of different MMPs. These enzymes are implicated in the growth, invasion and metastasis of multiple neoplasias, as they degrade the extracellular matrix in addition to facilitating the release of growth factors (3). Doxycycline has been shown to inhibit the activity of different MMPs and the in vitro proliferation of cells in breast cancer (MDA-MB-435 cells) (15), prostate cancer (LNCaP cells) (14) and osteosarcoma (U20S cells) (16).

MMP inhibitors (MMPIs), including doxycycline, are drugs that are currently being evaluated in the treatment of cancer. The results of the present study support the use of doxycycline as an adjuvant therapeutic agent for carcinoma of the duodenum. This type of cancer, in particular, is an uncommon disease, with a limited chemotherapy options (docetaxel, cisplatin and 5-fluorouracil) (17). Although doxycycline did not exert a curative effect in the animal model, it did reduce the speed of tumor growth and increased survival. This suggests that doxycycline and other MMPIs may be potential therapeutic options for adenocarcinoma of the duodenum.

In conclusion, doxycycline was shown to be a potential cytotoxic and antitumor agent for adenocarcinoma of the duodenum. However, further studies are required to evaluate the clinical usefulness of this drug and other MMP inhibitors in this type of cancer.

\section{References}

1. Bakaeen F, Murr MM, Sarr MG, Thompson GB, Farnell MB, Nagorney DM, Farley DR, van Heerden JA, Wiersema LM, Schleck CD and Donohue JH: What prognostic factors are important in duodenal adenocarcinoma? Arch Surg 135: 635-641; discussion 641-642, 2000.

2. Tocchi A, Mazzoni G, Puma F, Miccini M, Cassini D, Bettelli E and Tagliacozzo S: Adenocarcinoma of the third and fourth portions of the duodenum: Results of surgical treatment. Arch Surg 138: 80-85, 2003.

3. Hidalgo $\mathrm{M}$ and Eckhardt SG: Development of matrix metalloproteinase inhibitors in cancer therapy. J Natl Cancer Inst 93: 178-193, 2001.

4. Gu Y, Lee Hm, Sorsa T, Salminen A, Ryan ME, Slepian MJ and Golub LM: Non-antibacterial tetracyclines modulate mediators of periodontitis and atherosclerotic cardiovascular disease: A mechanistic link between local and systemic inflammation. Pharmacol Res 64: 573-579, 2011.
5. Leite LM, Carvalho AG, Ferreira PL, Pessoa IX, Gonçalves DO, Lopes Ade A, Góes JG, Alves VC, Leal LK, Brito GA and Viana GS: Anti-inflammatory properties of doxycycline and minocycline in experimental models: An in vivo and in vitro comparative study. Inflammopharmacology 19: 99-110, 2011.

6. Jantzie LL and Todd KG: Doxycycline inhibits proinflammatory cytokines but not acute cerebral cytogenesis after hypoxia-ischemia in neonatal rats. J Psychiatry Neurosci 35: 20-32, 2010.

7. Osten L, Kubitza M, Gallagher AR, Kastner J, Olbrich H, de Vries U, Kees F, Lelongt B, Somlo S, Omran H and Witzgall R: Doxycycline accelerates renal cyst growth and fibrosis in the pcy/pcy mouse model of type 3 nephronophthisis, a form of recessive polycystic kidney disease. Histochem Cell Biol 132: 199-210, 2009.

8. Soriano-Hernández AD, Galvan-SalazarHR,Montes-GalindoDA, Rodriguez-Hernandez A, Martinez-Martinez R, Guzman-EsquivelJ,Valdez-VelazquezLL,Baltazar-RodriguezLM, Espinoza-Gómez F, Rojas-Martinez A, et al: Antitumor effect of meclofenamic acid on human androgen-independent prostate cancer: A preclinical evaluation. Int Urol Nephrol 44: 471-477, 2012.

9. Sagar J, Sales K, Dijk S, Taanman J, Seifalian A and Winslet M: Does doxycycline work in synergy with cisplatin and oxaliplatin in colorectal cancer? World J Surg Oncol 7: 2, 2009.

10. Onoda T, Ono T, Dhar DK, Yamanoi A, Fujii T and Nagasue N: Doxycycline inhibits cell proliferation and invasive potential: Combination therapy with cyclooxygenase- 2 inhibitor in human colorectal cancer cells. J Lab Clin Med 143: 207-216, 2004

11. Onoda T, Ono T, Dhar Dk, Yamanoi A and Nagasue N: Tetracycline analogues (doxycycline and COL-3) induce caspase-dependent and -independent apoptosis in human colon cancer cells. Int J Cancer 118: 1309-1315, 2006.

12. Lokeshwar BL, Selzer MG, Zhu BQ, Block NL and Golub LM: Inhibition of cell proliferation, invasion, tumor growth and metastasis by an oral non-antimicrobial tetracycline analog (COL-3) in a metastatic prostate cancer model. Int J Cancer 98: 297-309, 2002

13. Wang A, Siegel E, Mayes DA, Hutchins LF and Yi Z: Anti-tumor effect of doxycycline on glioblastoma cells. Journal of Cancer Molecules 3: 147-153, 2007.

14. Fife RS, Sledge GW Jr, Roth BJ and Proctor C: Effects of doxycycline on human prostate cancer cells in vitro. Cancer Lett 127 37-41, 1998.

15. Fife RS and Sledge GW Jr: Effects of doxycycline on in vitro growth, migration, and gelatinase activity of breast carcinoma cells. Lab Clin Med 125: 407-411, 1995.

16. Fife RS, Rougraff TT, Proctor C and Sledge GW Jr: Inhibition of proliferation and induction of apoptosis by doxycycline in cultured human osteosarcoma cells. J Lab Clin Med 130: 530-534, 1997.

17. Bitik B,Kalpakci Y, Altan E,Dogan Eand Altundag K: Successful treatment of primary duodenal carcinoma with bilateral adrenal metastases with docetaxel-cisplatin-5-fluorouracil regimen. Ann Oncol 20: 394-395, 2009. 